\title{
How Economists Read Economic Texts
}

\author{
Stephanie M. Lemley \\ Mississippi State University \\ Rebecca C. Smith \\ Mississippi State University
}

Using a "think aloud" framework previously applied to history, this research leads the investigation in how economists read economics text to improve students' abilities to meet standards calling for reading, thinking, writing, and speaking like practitioners. Economic education has the reputation for being a difficult subject to teach and learn which is evidenced by disappointing individual and national economic literacy outcomes. This research finds precision, close reading, sourcing, and re-reading to be important practices of economists, and begins to fill the gap in the disciplinary literacy and economic education literatures providing direction for research and disciplinary literacy tools for educators.

Keywords: economic education, literacy, think-aloud, higher education, key practices

\section{INTRODUCTION}

A key idea of twenty-first century learning says students should think, read, write, and speak as a disciplinary practitioner (Common Core State Standards Initiative, 2010). Applied to the field of economics, this means that students should be reading and writing in the same manner that economists read and write. However, since literature in the discipline of economics focuses on the transmission of economic principles and concepts, it rarely attempts to explain how economists read and write. Additionally, current assessments and educational tools to help educators transmit economic education are targeted to building knowledge of economic concepts rather than on how economists actually read and write. Applying a "think aloud" framework, which is often applied to how historians read, to how economists read can provide a beginning to fill the gap in the related literature. Once we understand how economists read, this knowledge can be translated to non-economist educators seeking to improve their economic education practice.

Bruner (1960) postulates that education should serve as a means of training well-balanced citizens for a democracy. Lee (2007) furthered that argument, claiming that it is essential that students develop a depth of knowledge and skill in specific subjects, such as the social studies, subjects in order to become active participants in a democratic society. One way to support students in this manner is to teach them the structures of the disciplines, which Schwab (1962) defines as authentic disciplinary practices. This can be accomplished through integrating a disciplinary literacy perspective into instruction, which provides students with access to useable, everyday knowledge about a given discipline. This in turn allows them to evaluate ideas and act as informed citizens of the world (Moje, 2007). 
Literacy scholars have proposed that each discipline has its own specialized language, text structure, and ways of understanding what is on the page (Draper, Broomhead, Jensen, Nokes, \& Siebert, 2010; Moje, 2008; Shanahan \& Shanahan, 2008). A disciplinary perspective holds a more complex view of literacy instruction, addresses the literacy demands specific to a given discipline, and is based on the belief that deep knowledge of a particular discipline is best acquired by engaging in the literacy habits valued and used by experts in that discipline (Moje, 2008; Shanahan \& Shanahan, 2008). Disciplinary literacy perspectives are crucial, and the tools of knowledge production and knowledge critique should be uncovered, taught, and practiced in the classroom (Moje, 2008). Thus, this approach to teaching and learning integrates academically rigorous content with discipline-appropriate habits of thinking.

Although the idea of disciplinary literacy is a relatively new concept in literacy, the idea has a rich tradition in rhetoric and linguistics among those who are interested in writing in the disciplines (Bazerman, 1998; Hewings, 2005; Schleppegrell, 2004). In this research, we define disciplinary literacy as "the use of reading, investigating, analyzing, critiquing, writing, and reasoning required to learn and form complex knowledge in the [economics] discipline" (McConachie, 2010, p. 16). Moje (2008) argued that teachers must give students access to the oral and written language of the discipline if they are to learn deeply. Thus, literacy scholars note that the texts produced and used in a discipline, and the habits of mind and language should be the focus of disciplinary literacy instruction (Moje, 2008; Shanahan \& Shanahan, 2008).

The driving idea behind disciplinary literacy is that knowledge and thinking must go hand in hand. To develop deep conceptual knowledge in a discipline, students need to use the habits of thinking that are valued and used in that discipline. Conversely, in order for students to develop strategic and powerful discipline-specific habits of mind (e.g., thinking), they need to be directed by their content knowledge. This means that for students to become literate in a particular discipline, they must grow in both dimensions simultaneously (McConachie \& Petrosky, 2010). Specifically, they need a sound knowledge of economics content as well as of the specific ways to make sense of economics texts. Thus, the overarching goal of disciplinary literacy is that students will develop deep content knowledge and literate habits of thinking in the context of academically rigorous learning in individual disciplines, which create strategic readers.

Strategic readers are actively aware of the "mental dispositions necessary for comprehending a passage" (Billmeyer, 2009). This awareness, or metacognition, is rooted in the understanding that learners' schemas, or packets of knowledge, are activated or modified when they read a text. Embedded in these packets of knowledge, in addition to the knowledge itself, is information about how this knowledge is to be used. If one does not have the appropriate schema, he or she cannot understand the concept being communicated. Existing schemas may evolve or undergo changes to make them align more closely with new experiences. One may create new schema as well (Rumelart, 1980). Thus, individuals have different schema for the content of a text, reading processes, and different types of text; those differences in schema are related to differences in reading comprehension (Tracey \& Morrow, 2006).

Collins, Brown, and Larkin (1980) note that when individuals understand a text, they do not simply connect the events in the text in a sequential structure, rather they seem to create a complex scenario or model within which the events described might plausibly occur. Thus, proficient readers employ many metacognitive strategies (e.g., predicting, connecting, questioning, inferring) that assist them when reading a text independently. As such, these cognitive strategies need to be taught to learners. To that end, cognitive strategy instruction is an integral part of preparing leaners for success in the workplace and higher education (Conley, 2008). Researchers have found that metacognitive skills such as prediction, inference, and connection can be explicitly taught (Donovan \& Bransford, 2005; Pellegrino, 2007). Metacognitive strategies can also be used to allow learners to consider important questions they might pose or investigate while analyzing content (Pellegrino, 2007).

In the social sciences, researchers have focused much of their work on how historians make sense of a given text (e.g., Shanahan \& Shanahan, 2008; Wineburg, 1991) as well as how political scientists make sense of text (Voss, Greene, Post, \& Penner, 1983). Specifically, Wineburg (1991) found that historians employ three historical literacy heuristics when reading text: 1) sourcing, 2) corroboration, and 3) contextualization. Voss, Greene, Post, and Penner (1983) explained that political scientists engage in problem solving when reading about a political science issue; however, unlike the natural sciences, many 
of the problems found in political science do not have agreed upon solutions which can lead to argumentation in the field. Outside of the social sciences, Shanahan and Shanahan (2008) noted chemists focused on the different representations of the text when reading whereas mathematicians paid close attention to function words (e.g., a, and, the).

To date, no related work has been done for the field of economics. Good economic thinking is the foundation for deliberation on personal and public decision-making within democracies. However, while learning economics is of key importance to improved decision-making, economics has the reputation for being a difficult subject to teach, learn, and practice. Thus, the purpose of this study is to examine how economists read and make sense of disciplinary texts in order to improve the economics literacy skills of instructors and students.

\section{THEORETICAL FRAMEWORK}

The theory that undergirds this study is that of metacognition - thinking about one's own thinking. Hiebert and Raphael (1996) note, "The cognitive science revolution shifted the focus from the study of observable behaviors to attempts to describe unobservable mental processes" (p. 554). Reading a text is an unobservable mental process. Through work on cognition, researchers (Brown, 1978; Flavell, 1976; Pressley, 2000) have found that proficient readers engage in specific cognitive practices such as formulating questions, connecting text-to-text, inferring, and making predictions as they read a text. In addition, they use "fix up" metacognitive strategies when their comprehension falters. Tracey and Morrow (2006) posit that the goal of engaging in metacognitive practices is "to help readers become more aware of their own thinking during the reading process" (p. 62). Thus, metacognition plays a role in reading comprehension and problem solving (Flavell, 1979).

Metacognition is composed of two areas: metacognitive knowledge, a "person's declarative knowledge about the interactions between person, task, and strategy" and metacognitive skills, "a person's procedural knowledge for regulating one's problem-solving and learning activities" (Veenman, Van Hout-Wolters, \& Afflerbach, 2006, p. 4). According to Flavell (1979), there are three types of metacognitive knowledge: (a) strategic knowledge, (b) cognitive task knowledge, and (c) self-knowledge. Metacognitive knowledge requires a learner to use a set of strategies to help make sense of a given text, to know what the cognitive task is asking (e.g., recall, recognition, etc.), and to be self-aware of one's own knowledge base (Pintrich, 2002). With metacognitive skills, a learner either forges through a task successfully, or when comprehension breaks down, backtracks and starts again (Veenman, Van Hout-Wolters, \& Afflerbach, 2006).

\section{METHODOLOGY}

This was an exploratory study aimed to add to the knowledge base on how economists read subjectspecific texts. This study was guided by the following research question: What disciplinary literacy strategies do economists use when reading subject matter texts?

The verbal protocol analysis, also known as a "think-aloud" or a "verbal report" methodology (Ericsson and Simon 1993), that guided this investigation was heavily influenced by work done by Wineburg (1991) and Shanahan and Shanahan (2008). In verbal protocol analysis, subjects think aloud as they read a text. This methodology has been used in a variety of fields including physics, English, psychology, law, sociology, and history (Pressley \& Afflerbach 1995). In a think-aloud, the data reflects exactly what the subject is thinking about, even if the thought is not coherent (Ericsson \& Simon, 1993; Pressley \& Afflerbach, 1995). Further, think-alouds can be: (a) concurrent, where cognitive processes are verbalized immediately, (b) introspective, where observations of one's own cognitive processes occur, or (c) retrospective, which are given directly after the task is completed (Ericsson \& Simon, 1993; Pressley \& Afflerbach, 1995). In our work, we conducted a concurrent think-aloud. Our methodology choice was influenced by work by Shanahan and Shanahan (2008) and Wineburg (1991). In both of those studies, experts in various fields (e.g., history, chemistry, mathematics) read discipline-specific texts and thought 
aloud as they proceeded through the texts. As such, we desired to duplicate this methodology because it was effective in discovering discipline-specific practices in past work.

\section{Participants}

The data for this study are from three economists at a large, rural university in the southeastern part of the United States. Each holds a $\mathrm{PhD}$ and was at either the associate or full professor rank. Each economist was assigned a pseudonym. In our recruitment for the study, we aimed to recruit participants from different area of economics to provide a more comprehensive look at the field; therefore, we utilized purposeful sampling in our recruitment (Merriam, 2009). Alpha's area of expertise was agricultural economics, Beta's area was forestry economics, and Delta's area of expertise was in public finance and educational policy. All the participants were recognized for their excellence in teaching at the university level. As the second author is an economist, she facilitated the recruitment process.

\section{Data Sources and Analysis}

Each of the participants took part in one think-aloud protocol (Ericsson \& Simon, 1993) where they read three economics texts: (a) a portion of a high school textbook chapter on comparative advantage (see Appendix), (b) a New York Times opinion editorial on minimum wage by Christina Romer https://www.nytimes.com/2013/03/03/business/the-minimum-wage-employment-and-income-distribution. html, and (c) an article on income inequality from the St. Louis Federal Reserve https://fraser. stlouisfed.org/title/inside-vault-6107/spring-2010-586637.

The think-alouds lasted for an hour and a half each. After every two sentences, the participants stopped and talked about what they had read. The protocols were audio recorded, and if the participants forgot to stop and talk about what they were thinking, the researcher reminded them to do so by asking, "What are you thinking about now?"

After the think-aloud, the participants were each interviewed on the following topics within their field in economics: (a) terminology, (b) what types of texts they create and produce, and (c) what types of texts they read. The interviews lasted approximately forty-five minutes. Afterward, each of the think-aloud protocols and interviews was transcribed and returned to the participants for member checking (Merriam, 2009). During the member checking process, the participants were able to check their transcripts for accuracy.

Data were then analyzed using a constant comparative method for qualitative data analysis (Strauss \& Corbin, 1998). The data for both the think-aloud transcript and the interview were broken down into individual units for each participant and then coded to categories. Each case was analyzed individually and then we compared our individual results establishing validity in the coding process. Through cross-case analysis, descriptive categories were developed.

\section{RESULTS}

Analysis revealed four disciplinary literacy practices that economists engage in when reading subjectmatter texts: (a) preciseness, the act of being very deliberate in their language choices; (b) close reading, the act of careful and purposeful reading of data, charts, graphs, and figures, (c) sourcing, "the act of looking first to the source of the document before reading the body of the work" (Wineburg 1991, pg. 74); and (d) re-reading text, the act of reading a text again when comprehension breaks down. Each of these practices is elaborated on below.

\section{Preciseness}

Firstly, economists pay attention to precision of language, both in their own communication and in the documents they read. We define preciseness as the act of being deliberate in language choice. The economists scrutinized all three of the documents they were asked to read. Specifically, they were interested in the discipline-specific terminology used in each of the pieces and whether the pieces contained loaded or emotive language that attempted to influence the reader to any particular perspective. For example, in 
his interview, Beta posited, "There is a strong aversion to biased or non-objective analysis. Similarly, applied economists, avoid terms such as 'true' or 'false' to reflect the probabilistic hypothesis testing that dominated our work." In his think-aloud, Alpha noted that the authors of the textbook chapter used the term "better" to describe the different ways in which a country may be superior to another country. He said, "'Better' is a very loose term. I don't like it when my students use the term 'better.' I want them to explain what they mean." Later on in his think-aloud, the idea of being "better" resurfaced again. Alpha acknowledged that the authors of the text were now defining "better" in a more rigorous way by introducing the concepts of comparative and absolute advantage; however, he said it was still an "ill-defined term" to use because people can interpret that term to mean different things.

Further, the economists noted that when they come across someone who is using jargon incorrectly, they infer that the person was poorly trained, is a non-economist, or is someone who lacks credibility in the field. For example, Delta said,

There is a certain language all fields use. The average person does not know what I mean when I say "opportunity cost," but another economist would. I think some literacy is just a command of basic "econspeak" that one learns in a principles class. An understanding of econometrics terms gives you credibility in the field.

Each of the participants acknowledged that each economics sub-discipline has its own unique vocabulary. For instance, Delta said, "An experimental economist uses very specific language in discussing experimental design that an economist in another field - macroeconomic theory, for example-will likely not be familiar." Likewise, Beta noted that he demands his forestry students use the terminology set forth in his professional organization's The Dictionary of Forestry, since students need to communicate effectively about their field on a daily basis. He explained,

The essential tools of the [forestry] profession are to read, to understand what needs to be done, and then be able to write and speak about it on a daily basis. This is true from technical positions all the way up to the highest levels.

Therefore, per the participants, all economists need to be well-versed in basic terminology. They need also to be able to navigate through the various subfields of economics by accessing resources that will help them decipher specific, unfamiliar, sub-discipline vocabulary.

\section{Close Reading}

Secondly, the economists also performed a close reading of their text, which we define as the act of careful and purposeful reading of all text including data charts, graphs, and figures presented within. During close reading, the economists critiqued the figures presented in the texts. They each spent time meticulously examining the data for clarity and accuracy. For example, Delta commented on how it might be more useful for high school students if the figure in the high school economics textbook was displayed differently. Specifically, she noted that the end of the section in the textbook, which contained a mathematical figure and an explanation of the figure was "really dense" and that "students are not going to read that really closely because it's so dense." She further explained,

In fact I'm not wanting to read that closely and make sure their math is right, so then that becomes incumbent upon the instructor to go through that, and when they are teaching that material actually try to go through and actually show them the example.

However, while Delta did not want to close-read the data, she did in fact close-read the text. She spent quite a bit of time ( $\sim 2-3$ minutes) examining the data presented in the figure. She concluded, 
The only thing I would say about the last little bit is it gets really dense. You know going back for another example and I think you are-I mean-even for an economist reading it you have to go, 'okay wait we're trading what for what? And what was the ratio?' And so this is dense material for people to go through, and to really get it you have to very actively read it, and a high school student and even college students are not going to, I think, really read that closely.

Further, Alpha and Beta each commented on the importance of providing clear figures for the reader. Specifically, they have found many students struggle with economics because of the mathematical concepts, and if the figures in the text are not clear, this can hamper comprehension.

\section{Sourcing}

Like historians, the economists also source the document they are about to read. Wineburg (1991) defines sourcing as considering a document's attribution (both its author and how it came into being). During their think-aloud sessions, Alpha, Beta, and Delta examined each text to determine where it came from, who wrote it, and how it was written. They paid close attention to the type of publication they were reading and what they knew or did not know about the source. They considered where the piece came from and evaluated it accordingly. As Alpha noted, "Economists generally value and enforce logical reasoning. The gotcha in this profession is poor logic. Following from this foundation, mathematical rigor is valued, and mathematical proofs and derivations are respected." As such, the texts were examined carefully with regards to how the author presented his/her argument.

For example, one of the pieces was an opinion editorial from Christina Romer. The three economists paid close attention to the language used in the piece but also commented on what they knew about the author as well as her political background. For example, while reading the Romer piece, Alpha tried to remember if Romer was still serving in the Obama administration. He noted, "It's kind of interesting that she agrees and disagrees somewhat with the president that she once served. I think she would not have said this if she was still serving in the administration."

The piece from the St. Louis Federal Reserve, however, was viewed more carefully, and the economists expressed more criticism about that piece and its lack of references as compared to the Romer piece. Delta expressed surprise upon discovering that the piece on income inequality was from the St. Louis Federal Reserve. She believed the piece was biased towards one stance on income inequality. After examining the source of the publication, she said, "Oh, it's a Fed publication. And is it coming out of the St. Louis Fed? I'm surprised about the quality given it's a Fed publication."

At the end of his think aloud, Alpha compared the text from the St. Louis Federal Reserve to the piece by Christina Romer. Alpha commented,

I am struck by these two. I don't know the author [of the first piece] however Christina Romer is well known. My reading of [the Federal Reserve piece] is that this one is not well-documented and not using logic as it ought to. [On the other hand, article two] is and I don't think it's because I recognize the name as I read this article. This person [Romer] who worked in Washington at the head of the CEA, she understands the policy issues quite well, has a particular perspective, but is very - this is written in [a] more honest fashion [than the Federal Reserve piece].

The source of the text was an important consideration for all the economists. Specifically, there was a certain expectation of what was being presented and how it was being presented according to who the author of the text was and where that text came from. The economists placed a certain value on peer-reviewed, refereed publications compared to others like the editorial from Romer. Government publications also were also in high esteem in how regards to how language was used (e.g., biased, non-biased) as well as information presented. 


\section{Re-Reading}

Further, like mathematicians' economists re-read their texts. Specifically, when comprehension broke down, they went back and re-read the text. They looked back at the previous section comparing what the text says versus how the data are presented in the figure. In addition, when they came to parts of the text where their own comprehension broke down, they also went back and re-read as a "fix up" strategy. Understanding the numerical data and verifying that what is presented in charts, graphs, or other figures reflected in the text on a page was an important aspect of each participant's think-alouds. For example, when reading the St. Louis Federal Reserve piece, Beta went back and re-read some of the sections where the author presented data about the quintiles discussed in the article.

Beta also re-read a statement in the textbook excerpt, specifically an example about opportunity cost and trading bushels of wheat for bushels of corn. The statement read, "Remember that the opportunity cost of 1 bushel of wheat is 4 bushels of corn in Britain and 2 bushels of corn in the US. If the terms of trade are of such that 1 bushel of wheat trades for between 2 and 4 bushels of corn, both countries will gain from trade." After reading that statement, Beta paused and re-read the sentences again and hypothetically asked, "What does this mean? Giving up 4 bushels of corn is more costly?" After re-reading the statement, he paused again and went further back into the text to read the text leading up to the example, in addition to the entire example, yet again. He noted that his comprehension broke down as he was processing the example about bushels of corn and bushels of wheat.

Delta also had to go back and re-read the example about the bushels of corn and wheat because of the denseness of the material. She commented,

When presenting this material (comparative advantage and absolute advantage) it is easy to get bogged down and lose your intuition [when trying to make sense of the examples presented]. We want our students reading for background, and when it gets dense and they are having to go through to really understand the calculations, that makes it harder.

Based on the read-alouds performed by the participants, the data presented in all three texts warranted a re-read. The economists all discussed how important it was for individuals to understand the data presented in an economics text. The data, they emphasized, could not simply be overlooked because comprehension broke down. Rather, because it is a crucial part of an economics text, it needed to be closely read and re-read multiple times to improve comprehension.

\section{DISCUSSION}

One research question was considered for this study: What disciplinary literacy strategies do economists use when reading subject matter texts? The results of this study comprise the answers to that question and will be considered considering research on disciplinary literacy pedagogy and economics education.

The new targets (e.g., reading and comprehending complex informational text, incorporating disciplinary literacy instruction into classes, a focus on communication and critical thinking, academic vocabulary development) provided by the Common Core State Standards and the Partnership for $21^{\text {st }}$ Century Learning (P21) require new tools for economics educators (Common Core State Standards Initiative, 2010; Partnership for $21^{\text {st }}$ Century Learning, 2016). With an emphasis on implementing disciplinary literacy practices in the K-12 classroom (Lemley \& Hart, 2019; Lemley, Hart, \& King, 2019; Shanahan \& Shanahan, 2014; Shanahan \& Shanahan, 2008), it is necessary to discover what disciplinary practices experts use to make sense of discipline-specific texts. If economic literacy is tied to using contextualized content knowledge in one's thinking, more needs to be understood about what practicing economists read and how they process and evaluate information. This research identifies four practices used by economists when reading and comprehending economics text. This is a first step in determining relevant metrics, assessments, and scaffolding materials in the economics classroom. Improving disciplinary literacy skills of economics instructors is a first step in enabling learners to understand economics concepts in order 
to improve learners' practice of analytical reasoning which is the basis of all decision-making, both personal and public.

All four practices exhibited by the three economist participants in this study were considered "good reading behaviors" (Caldwell, 2008). Duke and Pearson (2002) noted that good readers are active, selective readers who pay attention to the vocabulary present in the text. In addition, they also evaluate the quality of a text and read text types in different ways. Further, they pay attention to their comprehension of the text and use metacognitive strategies such as re-reading as "fix ups" when their comprehension falters. All these characteristics were present in the three economists' readings of their discipline-specific texts. Pressley and Allington (2015) stated that it is important for good readers to reflect on their own comprehension of a text. The economists in this study were strategic, skilled readers when approaching each of the three texts. They were able to construct meaning because they brought a knowledge base to the texts, which shaped their comprehension of them (Duke, Pearson, Strachan, \& Billman, 2011).

As Wineburg (1991) found and Shanahan and Shanahan (2008) reaffirmed, sourcing is one important disciplinary practice that historians engage in when they make sense of text. As with historians, economists must consider the source of an economics text before they read. Further, Popp and Hoard (2018) and Jay's (2021) work supported the notion that sourcing can be taught in K-12 classrooms. In addition, Shanahan and Shanahan found that mathematicians re-read and close read mathematical data. Because so many of the texts that economists' read contain mathematical proofs and derivations, it makes sense that economists would also engage in such strategic processes.

The economists also emphasized the importance of understanding and using discipline-specific vocabulary when making sense of a text. Gee (2011) noted there are two types of discourse, "little-'d' discourse," which he defined as language-in-use (e.g., every day terminology) and "big-'d' Discourse," which encompasses more than language; it includes the language, speaking, writing, behaving, interacting, valuing, thinking, perspective taking, and believing associated with a specific community. According to Gee (2011), Discourse is a way of identifying people who are part of a particular community. Meaning is socially constructed, and within a Discourse community language is never neutral (Gee, 2011). The discipline-specific practices the economists engaged in during this study can serve as a way for learners to improve their own economic literacy. Economic literacy serves as a "means of communication among people, incorporating a basic vocabulary or logic that is so frequently encountered that the knowledge should be possessed by everyone" (Federal Reserve Bank of Minneapolis, 2016, n.p.).

Understanding basic economics is important for individuals and society for many reasons. For example, learners who understand economics understand how to apply the concept of opportunity cost, how economies work and how to use that knowledge to increase personal and firm-level productivity, how to turn income into wealth, how to recognize political rhetoric and keep politicians accountable, and how to recognize trends in data and patterns in relationships in order to evaluate different policies. Instructors and learners who have disciplinary literacy in economics have more background to consider both benefits and costs of personal and public decisions.

Defining and measuring "economic literacy" is a difficult proposition if one must capture the integration of economic thinking and economic knowledge in context (McConachie \& Petrosky, 2010). In a broad attempt, one would ideally want to consider using trends in personal saving rates, bankruptcy filings, profitability and productivity of firms, return on investment of government projects, and public debt. However, economics lacks "paternalism" and assumes individuals are better off relying on their own judgments. So, there is no external measure that can be used as a benchmark. Complicating matters even more is that "knowledge is not enough," and that even when individuals know what is likely to be in their long-run best interest, they do not always follow through. Further, political processes often trump good economics in group decision-making.

Given these constraints, attempts to measure comprehension of economic thinking have been largely limited to test scores focusing on content knowledge. The two nationally normed and standardized tests report low knowledge of economics content by high school students in the US. Neither instrument uses economics informational text in the questions. The Test of Economic Literacy (TEL) is a general achievement multiple-choice test measuring the understanding of content contained in the Council of 
Economic Education's content standards. The Fourth edition of the TEL reports an average overall score of approximately 23 correct questions out of 45 (Walstad, Rebeck, \& Butters, 2013). The National Assessment of Economics Progress (NAEP) Economics has multiple-choice and short- and longconstructed response questions spanning the domains of knowing, applying, and reasoning (National Center for Education Statistics, 2016). The NAEP Economics 2012 results show that basic economic literacy of U.S. twelfth graders has improved slightly since 2006, but a gap in the understanding of basic economic concepts persists; only 40 percent of students scored "Proficient" on the 2012 economics NAEP (National Center for Education Statistics, 2013).

One reason for the persistent gap in basic economic literacy is the difficulty teachers and learners have in understanding challenging economics concepts and the inability to use those concepts to practice analytical reasoning. Over time, more states have added an economics content requirement to the publicschool curriculum (Council for Economic Education, 2016). With the addition of more requirements comes the need for more teachers to have the ability to teach this "dismal science." However, research shows that many social studies teachers have less training in economics than any other social studies subject (Dumas, Evans, \& Weible 1997; Walstad \& Kourilsky 1999).

\section{CONCLUSIONS AND IMPLICATIONS}

This research is the first to apply the verbal protocol analysis, more commonly known as a "think aloud" to the field of economics. Instruction in economics is important for decision-making by individuals, households, firms, communities, nations, and the world. However, measures of economic literacy continue to show that much improvement is needed. This work sets the stage for a transformation within the field of economic education.

Using a "think-aloud" methodology with three academic economists and a limited number of text types, this study is an initial foray into such an exploration. In order to be able to generalize findings, future research should expand the variety of economists and include more variations of economic texts. This study finds the practices of precision, close reading, sourcing, and re-reading to be of key importance to how economists read economics texts. These findings reiterate the importance of exploring discipline-specific practices in various fields and provide new insights into discipline-based literacy pedagogy in the social sciences.

The findings from this study hold meaningful implications for those who work with elementary and secondary pre-service teachers in literacy methods classes; those working with elementary and secondary pre- and in-service economics teachers; economics instructors in college and universities; university research economists; and practitioners of economics attempting to convey their work clearly. As previous literacy researchers have noted (Bennett \& Hart, 2015; Hart \& Bennett, 2013; Moje, 2008; Zygorious-Coe, 2012), a disciplinary literacy pedagogical perspective requires knowledge about the content, discourses, and practices of a discipline.

An important implication of this research applies to the practice of economics instruction. What are the teaching practices in economics classrooms? If students are supposed to be reading, thinking, writing, and speaking as economists, some instruction time needs to focus on process rather than on principle-based content. This will take time and means covering a narrower variety of material in class. How does one, therefore, choose the most important principles and practices to cover? What do we know about what economists read, and how do we determine what the most important economics texts to be read in K-12, college, and universities are? Further, do educators have the skills to be able to read economics texts using precision, close reading, sourcing, and re-reading? What assessments and educational materials need to be created to help both economists and non-economists alike transmit these skills?

This research presents literacy and economic education researchers and economic educators an opportunity to embark on a shared conversation on how best to integrate content learning in a way that is meaningful to the student. This discussion among educators and researchers will include new ways to assess comprehension; rubrics on how to read, think, write, and speak like an economist; improving data analysis 
skills; and educational materials embracing disciplinary literacy strategies as well as additional research on how practicing economists process and evaluate economic text.

\section{REFERENCES}

Bazerman, C. (1998). Emerging perspectives on the many dimensions of scientific discourse. In J. Martin, \& R. Veel (Eds.), Reading science (pp. 15-30). New York, NY: Routledge.

Bennett, S.M., \& Hart, S.M. (2015). Addressing the 'shift': Preparing preservice secondary teachers for the Common Core. Reading Horizons, 53(4). Retrieved from http://scholarworks.wmich.edu/reading_horizons/vol53/iss $4 / 5$

Bennett, S.M., \& Hart, S.M. (2015). Addressing the 'shift': Preparing preservice secondary teachers for the Common Core. Reading Horizons, 53(4). Retrieved from $\mathrm{http} / / /$ scholarworks.wmich.edu/reading_horizons/vol53/iss $4 / 5$

Billmeyer, R. (2009). Creating thoughtful readers through habits of mind. Retrieved from http://www.ascd.org/publications/books/108014/chapters/Creating-Thoughtful-Readers-ThroughHabits-of-Mind.aspx

Brown, A.L. (1978). Knowing when, where, and how to remember: A problem of metacognition. In R. Glaser (Ed.), Advances in instructional psychology (Vol. 1, pp. 77-165). Hillsdale, NJ: Erlbaum.

Caldwell, J.S. (2008). Reading assessment: A primer for teachers (2nd ed.). New York, NY: Guilford Press.

Common Core State Standards Initiative. (2010). English language arts standards. Retrieved from http://www.corestandards.org/ELA-Literacy/

Conley, M.W. (2008). Cognitive strategy instruction for adolescents: What we know about the promise, what we don't know about the potential. Harvard Educational Review, 78(1), 84-106.

Council for Economic Education. (2014). Survey of the states economic and personal finance education in our nation's schools 2014. New York, NY: Author.

Council for Economic Education. (2016). Survey of the states economic and personal finance education in our nation's schools 2016. New York, NY: Author.

Donovan, M.S., \& Bransford, J.D. (2005). Introduction. In M.S. Donovan \& J.D. Bransford (Eds.), How students learn: History, mathematics, and science in the classroom (pp. 1-28). Washington, DC: The National Academy Press.

Draper, R.J., Broomhead, P., Jensen, A.P., Nokes, J.D., \& Siebert, D. (2010). (Re)Imagining content-area literacy instruction. New York, NY: Teacher College Press.

Duke, N.K., \& Pearson, P.D. (2002). Effective practices for developing reading comprehension. In A.E. Farsturp \& S.J. Samuels (Eds.), What research has to say about reading instruction (3rd ed., pp. 205-242). Newark, DE: International Reading Association.

Duke, N.K., Pearson, P.D., Strachan, S.L, \& Billman, A.K. (2011). Essential elements of fostering and teaching reading comprehension. In S.J. Samuels \& A.E. Farstrup (Eds.), What research has to say about reading instruction (4th ed., pp. 51-93). Newark, DE: International Reading Association.

Dumas, W., Evans, S., \& Weible, T. (1997). Minimum state standards for secondary social studies teacher license: A national update. The Social Studies, 88(3), 163-166.

Ericsson, K.A., \& Simon, H.A. (1993). Protocol analysis: Verbal reports as data. Cambridge, MA: MIT Press.

Federal Reserve Bank of Minneapolis. (2016). Why it's important to understand economics. Retrieved from https://www.minneapolisfed.org/publications/the-region/why-its-important-to-understandeconomics

Flavell, J.H. (1976). Metacognitive aspects of problem solving. In L.B. Resnick (Ed.), The nature of intelligence (pp. 231-235). Hillsdale, NJ: Erlbaum.

Flavell, J.H. (1979). Metacognition and cognitive monitoring a new area of cognitive-developmental inquiry. American Psychologist, 34(10), 906-911. 
Gee, J.P. (2011). An introduction to discourse analysis: Theory and method (3rd ed.). New York, NY: Routledge.

Hart, S.M., \& Bennett, S.M. (2013). Disciplinary literacy pedagogy development of STEM preservice teachers. Teacher Education \& Practice special issue. STEM Teacher Preparation and Practice: Prepare and Inspire Students, 23(2), 221-241.

Hewings, A. (2005). Developing discipline-specific writing: An analysis of undergraduate geography essays. In L. Ravelli \& R. Ellis (Eds.), Analysing academic writing: Contextualized frameworks (pp. 131-152). London, UK: Continuum.

Hiebert, E.H., \& Raphael, T.E. (1996). Psychological perspectives on literacy and extensions to educational practice. In D.C. Berliner \& R.C. Calfee (Eds.), Handbook of educational psychology (pp. 550-602). New York, NY; Simon \& Schuster Macmillan.

Jay, L. (2021). Revisiting Lexington green: Implications for teaching historical thinking. Cognition and Instruction, 39(3), 306-327.

Lemley, S.M., \& Hart, S.M. (2019). Using inquiry to develop agricultural education preservice teachers disciplinary literacy pedagogy. Journal of Agricultural Education, 60(4), 149-163. doi:10.5032/jae.2019.04149

Lemley, S.M., Hart, S.M., \& King, J.R. (2019). Teacher inquiry develops elementary teachers' disciplinary literacy. Literacy Research and Instruction, 58(1), 12-30. doi:10.1080/19388071.2018.1520371

McConachie, S.M. (2010). Disciplinary literacy: A principle-based framework. In S.M. McConachie \& A.R. Petrosky (Eds.), Content matters: A disciplinary literacy approach to improving student learning (pp. 15-32). San Francisco, CA: Jossey-Bass.

McConachie, S.M., \& Petrosky, A.R. (2010). Content Matters: A disciplinary literacy approach to improving student learning. San Francisco, CA: Jossey-Bass.

Merriam, S.B. (2009). Qualitative research: A guide to design and implementation. San Francisco, CA: Jossey-Bass.

Moje, E.B. (2007). Developing socially just subject-matter instruction: A review of the literature on disciplinary literacy teaching. Review of Research in Education, 31, 1-44.

Moje, E.B. (2008). Foregrounding the disciplines in secondary literacy teaching and learning: A call for change. Journal of Adolescent \& Adult Literacy, 52(2), 96-107.

National Center for Education Statistics. (2013). The Nation's Report Card: Economics 2012 (NCES 2013-453). Institute of Education Sciences, U.S. Department of Education, Washington, D.C.

National Center for Education Statistics. (2016). What does the NAEP Economics assessment measure? Retrieved from https://nces.ed.gov/nationsreportcard/economics/whatmeasure.aspx

Partnership for $21^{\text {st }}$ Century Learning. (2016). P21 framework for $21^{\text {st }}$ century learning. Retrieved from http://www.p21.org/storage/documents/docs/P21_framework_0816.pdf

Pellegrino, A.M. (2007). The manifestation of critical thinking and metacognition in secondary American history students through implementation of lesson plans and activities consistent with historical thinking skills. Electronic Theses, Treaties, and Dissertations Paper 2047.

Pintrich, P.R. (2002). The role of metacognitive knowledge in learning, teaching, and assessing. Theory Into Practice, 41(4), 219-225.

Popp, J.S., \& Hoard, J. (2018). Supporting elementary students' sourcing of historical texts. The Reading Teacher, 72(3), 301-311.

Pressley, M., \& Allington, R.L. (2015). Reading instruction that works: The case for balanced teaching (4th ed.). New York, NY: Guilford Press.

Rumelhart, D.E. (1980). Schemata: The building blocks of comprehension. In R.J. Spiro, B.C. Bruce, \& W.F. Brewer (Eds.), Theoretical issues in reading comprehension: Perspectives from cognitive psychology, linguistics, artificial intelligence, and education (pp. 33-58). Hillsdale, NJ: Lawrence Erlbaum Associates.

Schleppegrell, M.J. (2004). The language of schooling: A functional linguistics perspective. Mahwah, NJ: Erlbaum. 
Schwab, J.J. (1962). The concept of the structure of a discipline. The Educational Record, 43, 197-205.

Shanahan, C., \& Shanahan, T. (2014). Does disciplinary literacy have a place in elementary school? The Reading Teacher, 67(8), 636-639.

Shanahan, T., \& Shanahan, C. (2008). Teaching disciplinary literacy to adolescents: Rethinking contentarea literacy. Harvard Educational Review, 78(1), 40-59.

Strauss, A., \& Corbin, J. (1998). Basics of qualitative research: Techniques and procedures for developing grounded theory (2nd ed.). Thousand Oaks, CA: Sage.

Tracey, D.H., \& Morrow, L.M. (2006). Lenses on reading: An introduction to theories and models. New York, NY: The Guilford Press.

Veenman, M.V.J., van Hout-Wolters, B.H.A.M., \& Afflerbach, P. (2006). Metacognition and learning: Conceptual and methodological considerations. Metacognition and Learning, 1(1), 3-14.

Voss, J., Greene, T., Post, T., \& Penner, B. (1983). Problem solving in the social studies. In G.H. Bower (Ed.), Psychology of learning and motivation (pp. 165-213). New York, NY: Academic Press.

Walstad, W., \& Kourilsky, M. (1999). Seeds of success: Entrepreneurship and youth. Dubuque, IA: Kendall-Hunt.

Walstad, W.B., Rebeck, K., \& Butters, R.B. (2013). The Test of Economic Literacy: Development and results. The Journal of Economic Education, 44(3), 298-309. doi:10.1080/00220485.2013.795462

Wineburg, S.S. (1991). Historical problem solving: A study of the cognitive processes used in the evaluation of documentary and pictorial evidence. Journal of Educational Psychology, 83(1), 7387. doi:10.1037//0022-0663.83.1.73

Zygouris-Coe, V.I. (2012). Disciplinary literacy and the Common Core state standards. Topics in Language Disorders, 32(1), 35-50. 


\section{APPENDIX}

642 ChAPTER 18 . Trade and the Global Economy

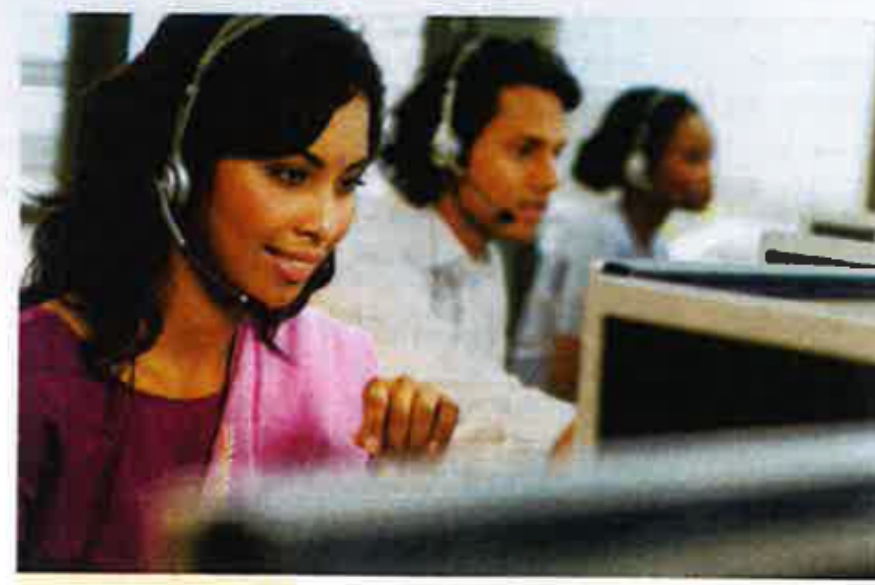

If indian call centers can handle more colls per hour than British coll centers, Indio has an absolute advantage in providing call center services.

A country has an absolute advantage in the production of a good if it can produce more of that good than its trading partner using a given quantity of resources.

A country has a comparative advantage in the production of a good if it can produce the good at a lower opportunity cost than its trading partner.

\section{Absolute Advantage}

If one country can produce more of something than another country using a given quantity of resources, the more productive country has an absolute advantage. Adam Smith introduced the concept of absolute advantage with examples of two countries producing goods with labor as the resource. Consider the call centers that companies like Microsoft and Delta employ to provide customer assistance and sell things like airline reservations. If workers in Indian call centers can handle 20 calls per hour and workers in British call centers can handle 15 calls per hour, then India has an absolute advantage in providing call center services.

Adam Smith discussed absolute advantage as a basis for trade, suggesting that countries should specialize in those goods in which they have an absolute advantage and trade for the goods they most desire. However, it is possible for one country to have an absolute advantage over its potet tial trading partners in most ot all $\mathrm{gocos}_{\mathrm{O}}$ and yet benefit from trade with othe countries (as explained in the next tion). So having an absolute advant in producing a particular good does no determine whether that country shoul import or export that good. An absolute advantage does help a country prode goods at a relatively low financial cost and in relative abundance, for use in trade of for consumption in that country.

\section{Comparative Advantage}

David Ricardo, a classical economist hisp Adam Smith, developed the concept of comparative advantage. When one country can produce a good at a lower opporth nity cost than another country, it has ? comparative advantage in produc. ing that good. Recall that having a lown opportunity cost means that the countm gives up less of the next-best alternatity good when it produces another unit of the good in question. For example, sup pose that the opportunity costs of pro ducing wheat and corn in Britain and the United States are as shown in Table 532 For each additional bushel of wheat pro duced in Britain, 4 fewer bushels of corn can be produced. The opportunity $\cos$ of a bushel of wheat is then 4 bushels of corn. The United States can produce bushel of wheat at an opportunity costo 2 bushels of corn. In this case the United States has a comparative advantage in wheat production because the United States gives up less corn than Britain to get each bushel of wheat. That is, the United States has a lower opportunity cost.

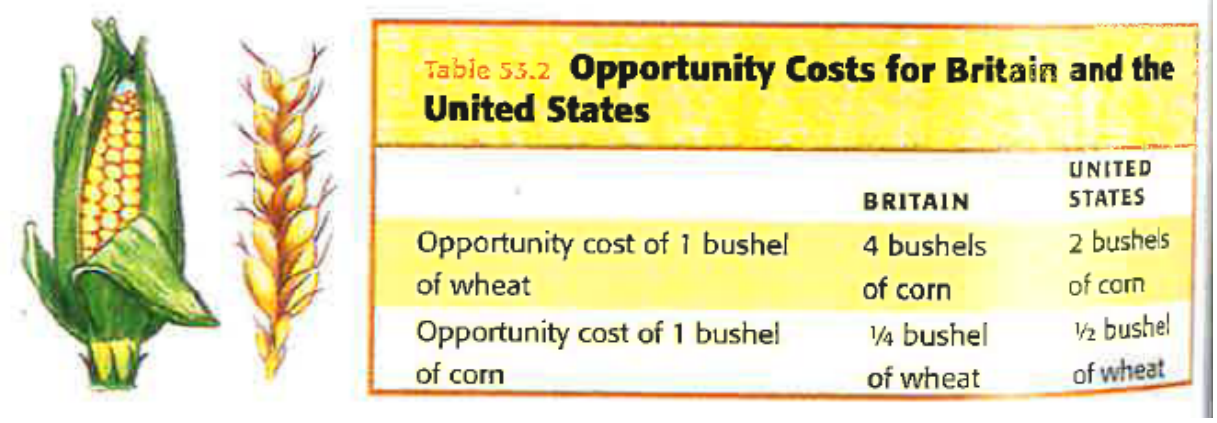




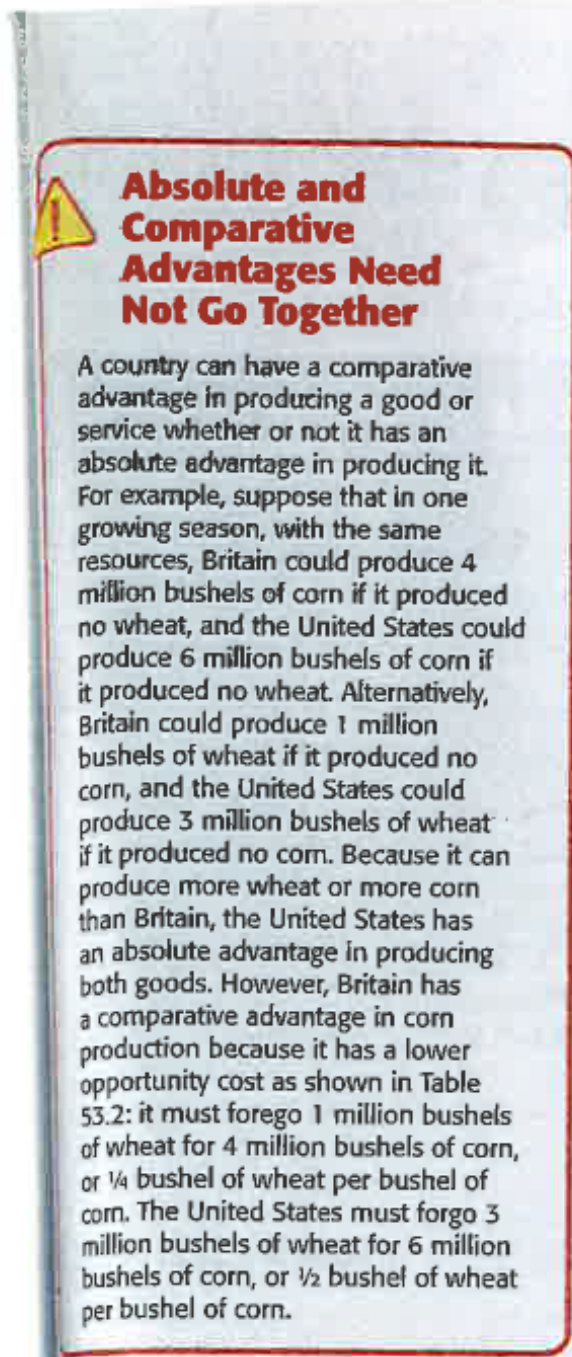

Because the United States has a comrative advantage in wheat production, vitain has a comparative advantage in m production. Since Britain gives up 4 sheis of corn per bushel of wheat, each shel of corn substitutes for only $1 / 4$ of bushel of wheat. The opportunity cost corn in Britain is thus $1 / 4$ of a bushel wheat. In the United States, where 1 whel of wheat reduces corn production 2 bushels of corn, each bushel of corn stitutes for $1 / 2$ bushel of wheat, so the portunity cost of a bushel of corn in United States is $1 / 2$ bushel of wheat. ith the lower opportunity cost of $1 / 4$ shel of wheat, Britain gives up less eat to get each bushel of corn, so it ynd has a comparative advantage in in production.
A simple way to find the opportunity cost of, say, corn is to look at what happens when a country switches from making only wheat to making only corn. Suppose Britain can make 1 million bushels of wheat if it produces only wheat, but by foregoing all 1 million bushels of wheat it can make 4 million bushels of corn. Then the opportunity cost of 1 bushel of corn for Britain is

$$
\begin{gathered}
\begin{array}{c}
\text { change in quantity } \\
\text { of wheat }
\end{array} \\
\begin{array}{c}
\text { change in quantity } \\
\text { of corn }
\end{array}
\end{gathered}=\frac{1 \text { million }}{4 \text { million }}=1 / 4
$$

In their actual farming practices it is unlikely that a country would go from the extreme of making no com to the extreme of making no wheat-Britain and the United States produce some of both goods. But looking at the extreme possibilities simplifies opportunity cost calculations.

Ricardo reasoned that whenever a country has a comparative advantage over another country in the production of a good, it is a certainty that both countries can benefit from trade. In our example, the United States has a comparative advantage in wheat production and Britain has a comparative advantage in com production, so the United States should specialize in wheat production and trade it for corn from Britain. Remember that the opportunity cost of 1 bushel of wheat is 4 bushels of com in Britain and 2 bushels of corn in the United States. If the terms of trade are such that 1 bushel of wheat trades for between 2 and 4 bushels of corn, both countries will gain from trade. For example, suppose 1 bushel of wheat from the United States trades for 3 bushels of corn from Britain. Instead of giving up 4 bushels of corn per bushel of wheat as it would without trade, Britain will only give up 3 bushels of corn per bushel of wheat-an improvement for Britain! And rather than giving up $1 / 2$ bushel of wheat for every bushel of corn as it would without trade, the United States is paying 1 bushel of wheat for 3 bushels of corn, which is only $1 / 3$ bushel
When a country with a comparative advantage in com production exports com to a country with a comparative advantage in something else, both countries can enjoy more of both goods than in the absence of trade.

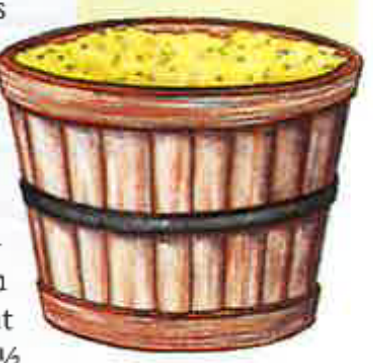

